Article

\title{
Herbal Combination of Phyllostachys pubescens and Scutellaria baicalensis Inhibits Adipogenesis and Promotes Browning via AMPK Activation in 3T3-L1 Adipocytes
}

\author{
Yoon-Young Sung ${ }^{1}$, Eunjung Son ${ }^{1}$, Gayoung Im ${ }^{2}$ and Dong-Seon Kim ${ }^{1, *}$ \\ 1 Herbal Medicine Research Division, Korea Institute of Oriental Medicine, 1672 Yuseong-daero, Yuseong-gu, \\ Daejeon 34054, Korea; yysung@kiom.re.kr (Y.-Y.S.); ejson@kiom.re.kr (E.S.) \\ 2 Nova K Med Co., Ltd., 1646 Yuseong-daero, Yuseong-gu, Daejeon 34054, Korea; imci85@novarex.co.kr \\ * Correspondence: dskim@kiom.re.kr; Tel.: +82-42-868-9639
}

Received: 16 September 2020; Accepted: 22 October 2020; Published: 23 October 2020

\begin{abstract}
To investigate the anti-obesity effects and underlying mechanism of BS21, a combination of Phyllostachys pubescens leaves and Scutellaria baicalensis roots was used to investigate the effects of BS21 on adipogenesis, lipogenesis, and browning in 3T3-L1 adipocytes. The expression of adipocyte-specific genes was observed via Western blot, and the BS21 chemical profile was analyzed using ultra-performance liquid chromatography (UPLC). BS21 treatment inhibited adipocyte differentiation and reduced the expression of the adipogenic proteins peroxisome proliferator-activated receptor $\gamma(\mathrm{PPAR}-\gamma), \mathrm{CCAAT} /$ enhancer-binding protein $(\mathrm{C} / \mathrm{EBP}-\alpha)$, and adipocyte protein $2(\mathrm{aP} 2)$, as well as the lipogenic proteins sterol regulatory element-binding protein 1c (SREBP-1c) and fatty-acid synthase (FAS). BS21 enhanced protein levels of the beta-oxidation genes carnitine palmitoyltransferase (CPT1) and phospho-acetyl-coA carboxylase (p-ACC). BS21 also induced protein expressions of the browning marker genes PR domain containing 16 (PRDM16), peroxisome proliferator-activated receptor gamma co-activator 1-alpha (PGC1 $\alpha$ ), and uncoupling protein (UCP) 1 , and it induced the expression of the thermogenic gene UCP2. Furthermore, BS21 increased adenosine monophosphate-activated protein kinase (AMPK) activation. UPLC analysis showed that BS21 contains active constituents such as chlorogenic acid, orientin, isoorientin, baicalin, wogonoside, baicalein, tricin, wogonin, and chrysin. Our findings demonstrate that BS21 plays a modulatory role in adipocytes by reducing adipogenesis and lipogenesis, increasing fat oxidation, and inducing browning.
\end{abstract}

Keywords: adipogenesis; AMPK; anti-obesity; triglycerides; UCP1

\section{Introduction}

Obesity is the main risk factor for several metabolic abnormalities including hyperlipidemia, atherosclerosis, type 2 diabetes, dyslipidemia, and hypertension [1]. Obesity develops following a prolonged period of positive energy imbalance when food intake exceeds total energy expenditure, which must be reversed for treatment to be successful [2,3]. New approaches for promoting energy consumption are emerging to inhibit energy intake (appetite or absorption) [4]. Brown adipocytes in brown adipose tissue (BAT) expend stored energy and produce heat via the expression of brown fat-specific uncoupling protein (UCP) 1 [5]. Beige adipocytes are inducible brown-like fat cells in white adipose tissue (WAT) that can consume stored energy following exposure to adrenergic signaling or chronic cold through UCP1-mediated thermogenesis, and recent treatments for obesity have increased the therapeutic interest in browning of WAT [6]. 
Adenosine monophosphate-activated protein kinase (AMPK) is an intracellular energy sensor that regulates energy balance and acts as a metabolic switch [7]. AMPK stimulates adenosine triphosphate (ATP)-producing catabolic pathways (e.g., lipolysis or fatty-acid oxidation) and switches off ATP-consuming anabolic pathways (e.g., lipogenesis) that increase energy production and consumption, respectively [8]. Thus, the development of AMPK activators has become a therapeutic target for obesity [9].

Bamboo leaves, usually as tea, have been used for more than 1000 years in Asia for nutrition and as herbal medicine and have various biological functions, including antibacterial, antiviral, and anti-atherosclerosis activities [10]. The antioxidant and anticoagulant effects of Phyllostachys pubescens Mazel (Bamboo, Poaceae family) leaves have been reported [11]. It was recently reported that bamboo leaves and its major flavonoid, isoorientin, inhibited adipogenesis in adipocytes [12,13]. Scutellaria baicalensis Georgi (Baikal skullcap, family: Lamiaceae family) roots (S) have been used in traditional medicine. These roots have diuretic, anti-diarrhea, and anti-inflammation effects [14] and were recently reported to reduce body weight and improve serum lipid levels in mice $[15,16]$. Baicalin in S. baicalensis exhibited anti-obesity effects through enhanced fatty-acid oxidation [17]. Our recent study suggested that various mixtures of P. pubescens leaves and S. baicalensis roots (BS) had anti-obesity effects in obese mice fed a high-fat diet, and a 2:1 (w:w) mixture of the two plant extracts (BS21) was most effective in decreasing body weight gain and normalizing serum lipid profiles [18]. However, the anti-obesity effects of BS21 and its underlying mechanisms in adipocytes have not been explored. This study examined the effect of BS21—the most effective combination-on adipogenesis and browning in 3T3-L1 adipocytes. Ultra-performance liquid chromatography (UPLC) was performed to determine the constituents of BS21 and assess which constituent inhibited adipogenesis.

\section{Results}

\subsection{Effect of BS21 on Adipocyte Differentiation and Lipolysis in 3T3-L1 Cells}

Preadipocytes were stained with fat-specific Oil Red $\mathrm{O}$ after inducing adipocyte differentiation in MDI (3-isobutyl-1-methylxanthine, dexamethasone, and insulin) differentiation media (Figure 1A,B). Oil Red O staining quantification demonstrated that treatment with $60,120,240$, and $480 \mu \mathrm{g} / \mathrm{mL}$ concentrations of BS21 significantly decreased adipocyte differentiation as well as the accumulation and size of lipid droplets, as shown by a $\approx 50 \%$ decrease in fat accumulation with $240 \mu \mathrm{g} / \mathrm{mL}$ treatment. After adipocyte differentiation, the secreted levels of adipokines (leptin and adiponectin) were measured in the supernatant (Figure 1C). BS21 at concentrations of 240 and $480 \mu \mathrm{g} / \mathrm{mL}$ attenuated an increase in leptin levels following differentiation, and $480 \mu \mathrm{g} / \mathrm{mL}$ also decreased adiponectin levels. The glycerol concentration in culture supernatants was used as a marker for adipocyte lipolysis. As shown as Figure 1D, BS21 did not increase lipolysis. Rather, $400 \mu \mathrm{g} / \mathrm{mL}$ of BS21 decreased glycerol levels. None of these extracts affected cell viability after 24 or $48 \mathrm{~h}$ treatment at any concentration tested (Figure 1E). 


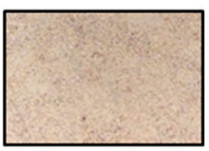

Control

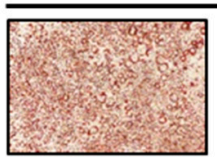

0

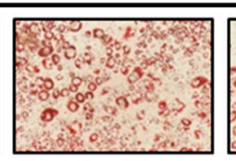

60

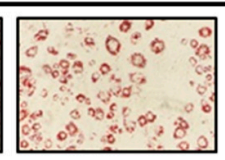

120

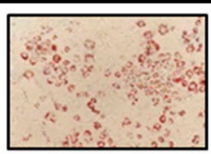

240

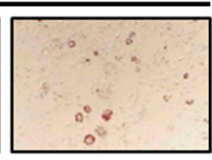

480

$\mu \mathrm{g} / \mathrm{mL}$

(A)

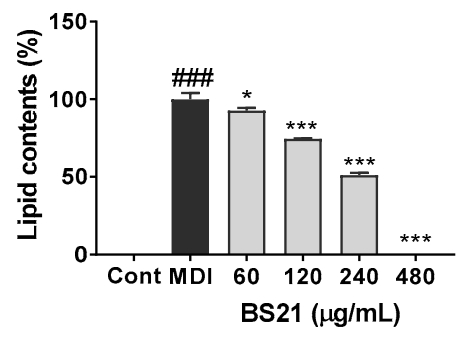

(B)

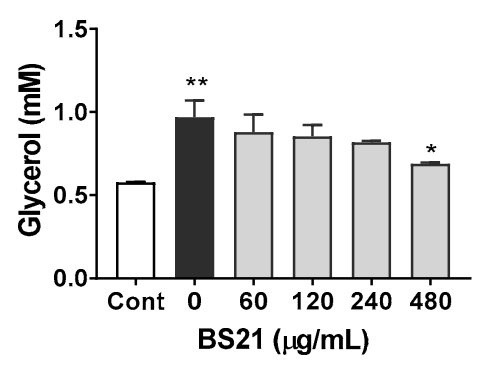

(D)

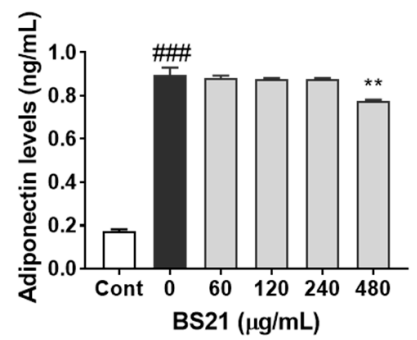

(C)

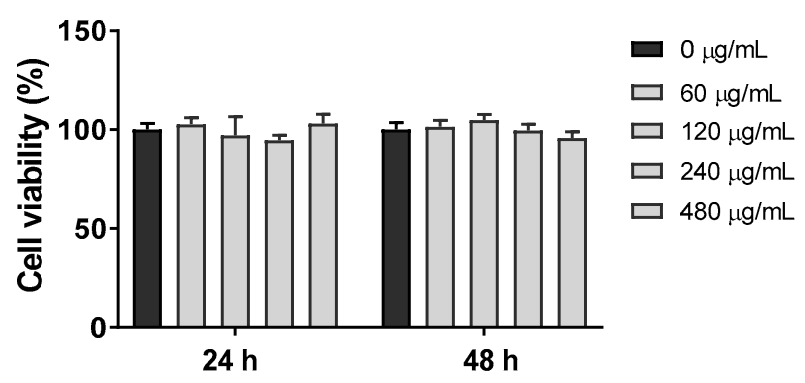

(E)

Figure 1. Effect of a 2:1 mixture of Phyllostachys pubescens and Scutellaria baicalensis (BS21) on adipocyte differentiation in 3T3-L1 cells. (A) Oil Red O staining of intracellular triglycerides in 3T3-L1 cells. 3T3-L1 cells were treated with BS21 $(60,120,240$, and $480 \mu \mathrm{g} / \mathrm{mL})$ during differentiation induction. (B) Relative densities of lipid contents. (C) Leptin and adiponectin levels in cell supernatants. (D) Glycerol levels in differentiated cells. (E) Cell viability. Values are expressed as means \pm SD $(n=3)$. Significant differences were observed between control (undifferentiated preadipocytes) and differentiated MDI (3-isobutyl-1-methylxanthine, dexamethasone, and insulin) cells: \# $p<0.05$, $\# \# p<0.01$, and \#\#\# $p<0.001$. Significant differences were observed between differentiated MDI cells and BS21-treated cells: ${ }^{*} p<0.05,{ }^{* *} p<0.01$, and ${ }^{* * *} p<0.001$.

\subsection{Effect of BS21 on Adipocyte Marker Protein Expression in 3T3-L1 Cells}

We next confirmed the expression of white adipocyte marker proteins in 3T3-L1 cells. BS21 treatment for 7 days significantly reduced the protein expression of white adipocyte markers (peroxisome proliferator-activated receptor $\gamma(\operatorname{PPAR} \gamma), \mathrm{CCAAT} /$ enhancer-binding protein $(\mathrm{C} / \mathrm{EBP} \alpha)$, and adipocyte protein 2 (ap2)) and lipogenic markers (sterol regulatory element-binding protein (SREBP1c) and fatty-acid synthase (FAS)) in a dose-dependent manner (Figure 2A,B). Expression levels of the $\beta$-oxidation proteins (CPT1 and p-ACC) were significantly increased by $400 \mu \mathrm{g} / \mathrm{mL}$ BS21. The phosphorylation of the lipolysis gene HSL decreased with BS2. These results suggest that BS21 can regulate lipid metabolism in 3T3-L1 adipocytes. 


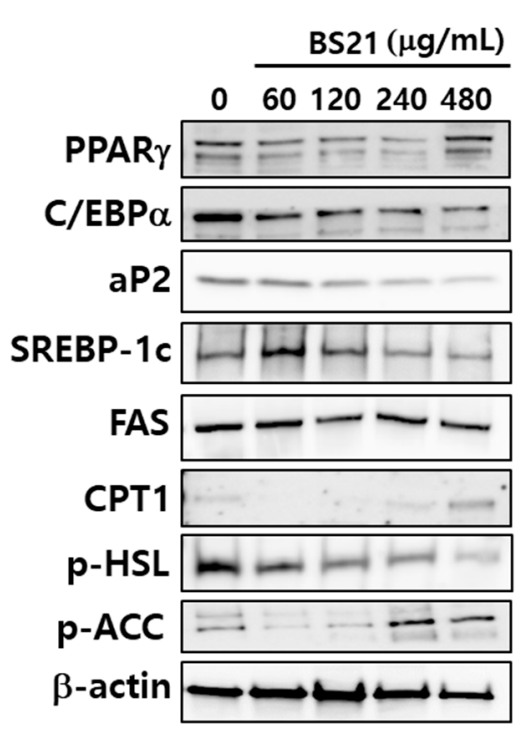

(A)
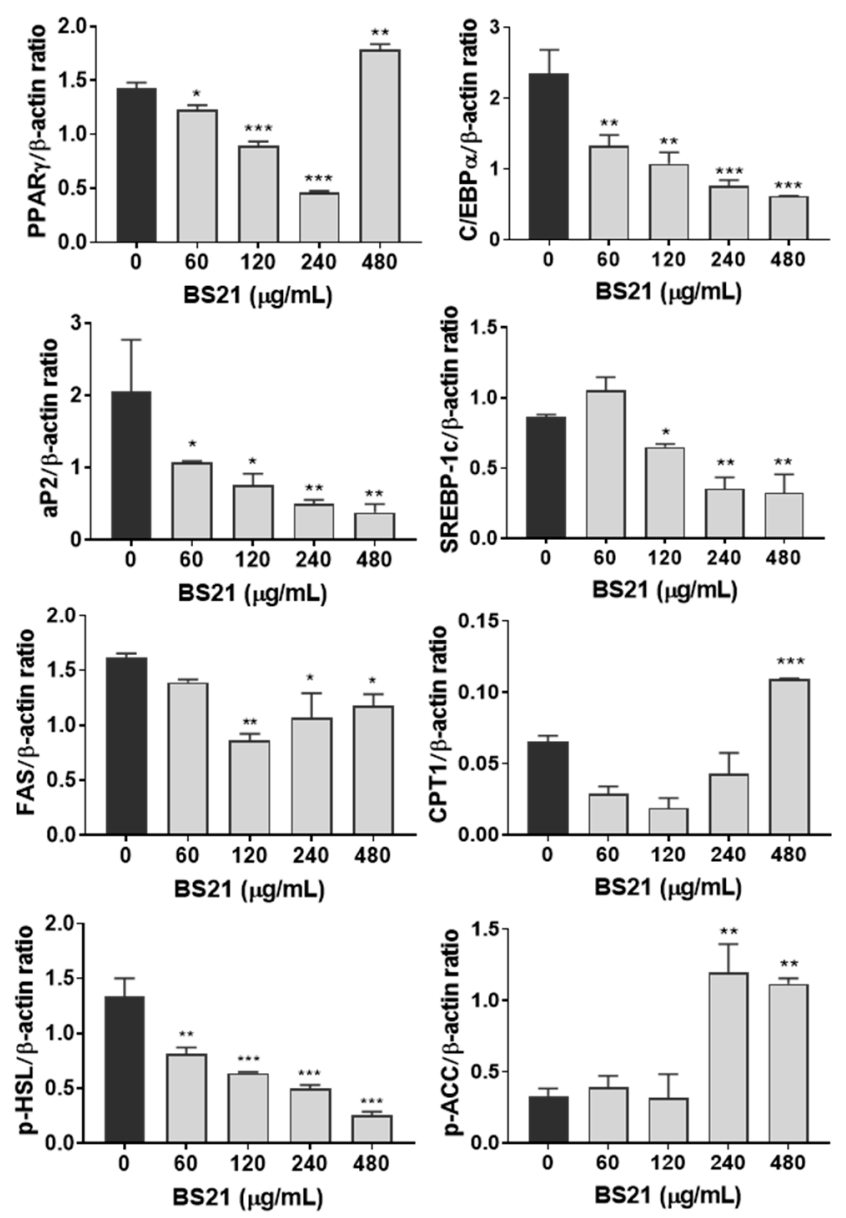

(B)

Figure 2. Effect of a 2:1 mixture of Phyllostachys pubescens and Scutellaria baicalensis (BS21) on lipid metabolism-related protein expression in 3T3-L1 cells. (A) Representative bands and (B) relative changes in protein expression levels. The relative expression levels of proteins were normalized against a $\beta$-actin internal control. Values are expressed as means $\pm \operatorname{SD}(n=3)$. Significant differences were observed between differentiated MDI (3-isobutyl-1-methylxanthine, dexamethasone, and insulin) cells and BS21-treated cells: ${ }^{*} p<0.05,{ }^{* *} p<0.01$, and ${ }^{* * *} p<0.001$.

\subsection{Effect of BS21 on Browning and AMPK Signaling in 3T3-L1 White Adipocytes}

To assess whether BS21 regulates browning, we measured the protein levels of browning marker genes. BS21 at concentrations of 240 and $480 \mu \mathrm{g} / \mathrm{mL}$ induced expressions of specific brown fat proteins UCP1, PRDM16, and PGC1 $\alpha$ as well as the thermogenesis-related gene UCP2 (Figure 3A,B). 


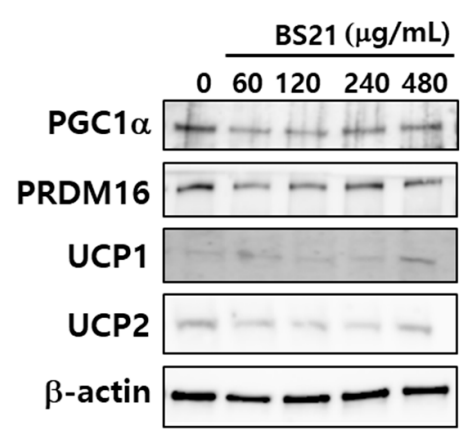

(A)
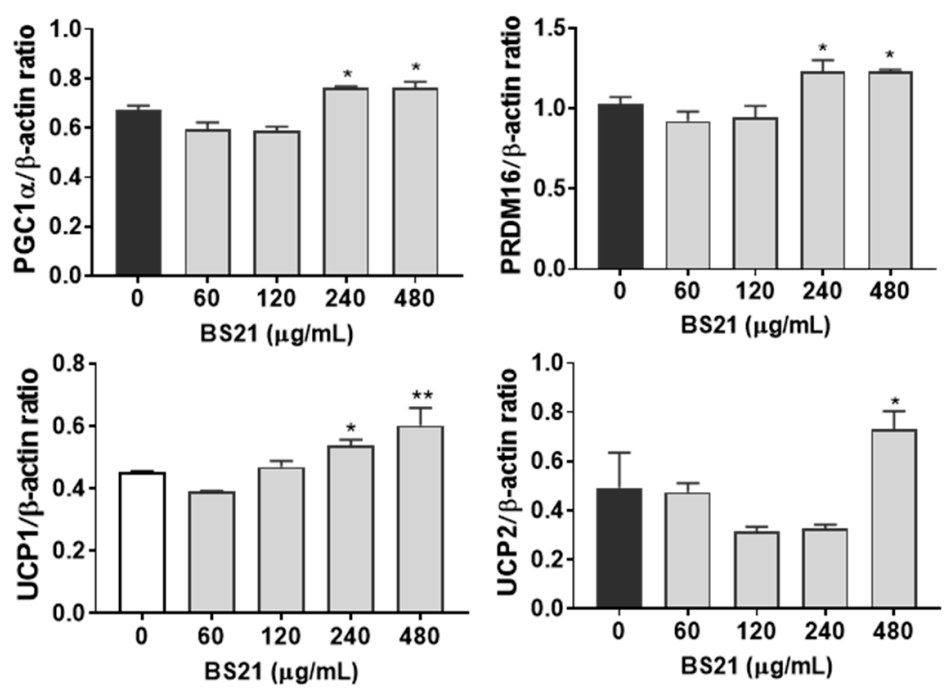

(B)
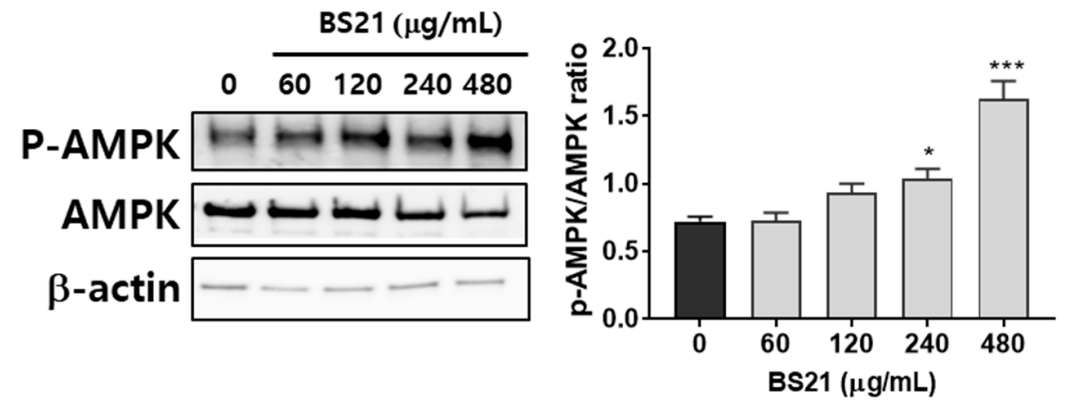

(C)

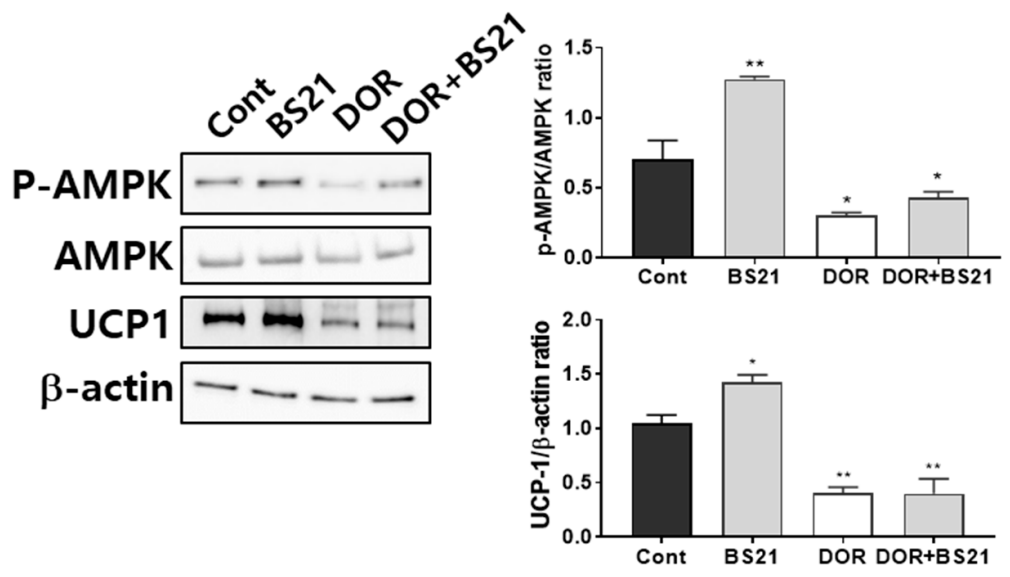

(D)

Figure 3. Effect of a 2:1 mixture of Phyllostachys pubescens and Scutellaria baicalensis (BS21) on brown adipocyte-specific protein expression and adenosine monophosphate-activated protein kinase (AMPK) phosphorylation in 3T3-L1 cells. (A) Representative bands and (B) relative changes in protein expression levels. The relative expression levels of proteins were normalized against a $\beta$-actin internal control. (C) Representative bands and relative changes in p-AMPK and AMPK protein levels are shown. Target-protein phosphorylation was normalized to the total protein-expression level. (D) 3T3-L1 adipocytes were pretreated with the p-AMPK antagonist dorsomorphin $(5 \mu \mathrm{M})$ in addition to BS21 at differentiation stages. Values are expressed as mean $\pm \operatorname{SD}(n=3)$. Significant differences were observed between differentiated MDI (3-isobutyl-1-methylxanthine, dexamethasone, and insulin) cells and BS21-treated cells: ${ }^{*} p<0.05,{ }^{* *} p<0.01$, and ${ }^{* * *} p<0.001$. 


\subsection{Effect of BS21 on AMPK Signaling in 3T3-L1 Cells}

We next investigated whether BS21 affects lipid metabolism and browning via AMPK. BS21 at concentrations of 240 and $480 \mu \mathrm{g} / \mathrm{mL}$ increased AMPK phosphorylation (Figure 3C). This finding suggested that the increased lipid metabolism and browning effect in BS21-treated 3T3-L1 adipocytes could be mediated by AMPK activation. To further examine the AMPK signaling mechanism of the browning effects of BS21, we treated an AMPK antagonist (dorsomorphin). Elevated UCP1 expression was diminished by treatment with dorsomorphin (Figure 3D). These results indicate that BS21 induced the browning of 3T3-L1 adipocytes by enhancing AMPK phosphorylation.

\subsection{Effect of Nine Major BS21 Compounds on 3T3-L1 Adipocyte Differentiation}

UPLC analysis showed that BS21 contained chlorogenic acid, orientin, baicalin, wogonoside, baicalein, tricin, wogonin, and chrysin (Figure 4 and Table 1). Groups of cells were treated with one of the nine compounds at concentrations of 10 and $50 \mu \mathrm{g} / \mathrm{mL}$, and all compounds significantly reduced adipocyte differentiation and leptin levels except for wogonoside (Figure 5A-C). In particular, baicalein and baicalin at $10 \mu \mathrm{g} / \mathrm{mL}$ inhibited adipocyte differentiation by $50 \%$ compared with the differentiated MDI cells. These compounds did not affect cell viability at all concentrations tested (Figure 5D).

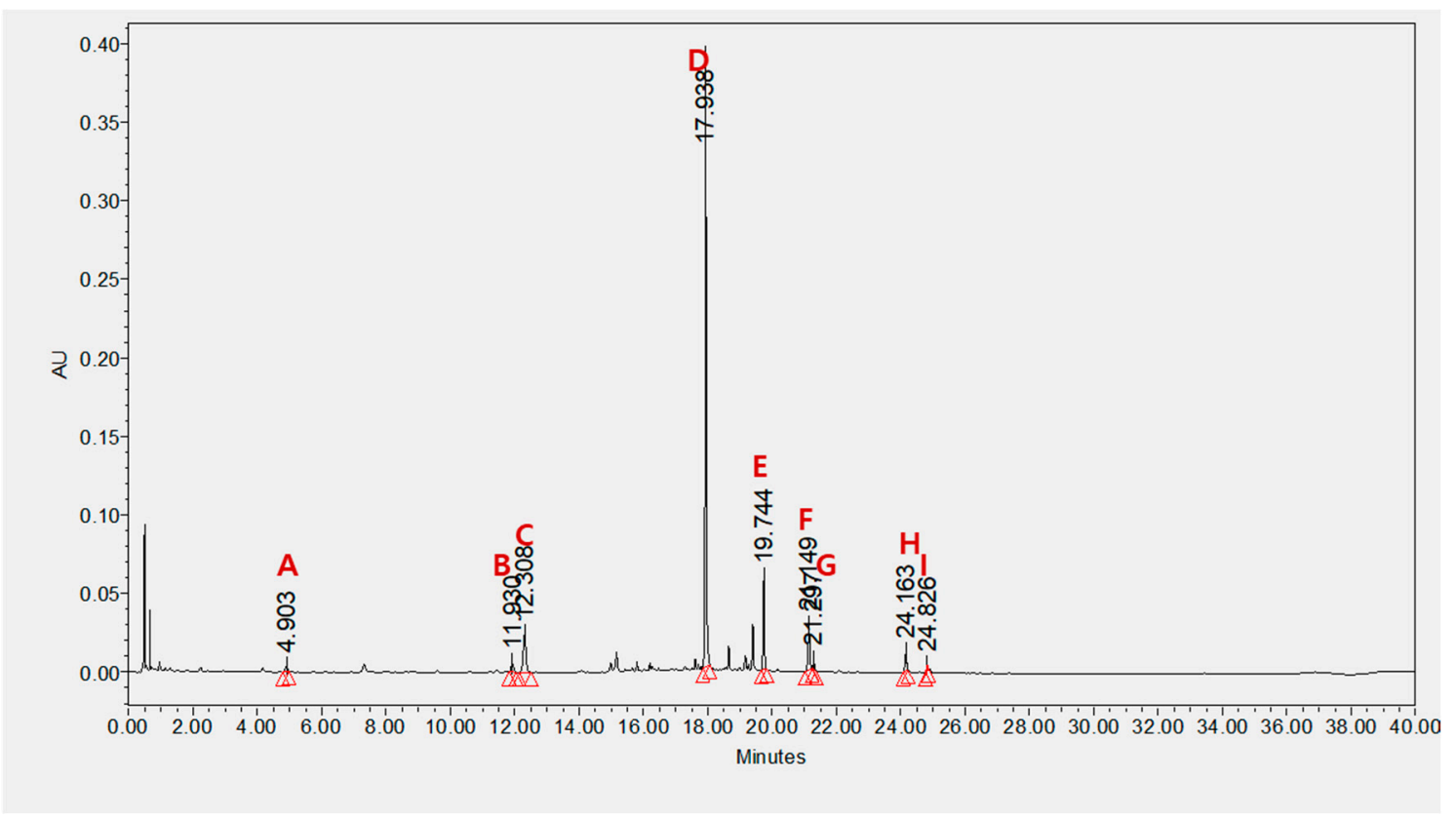

Figure 4. Identification and quantitative analysis of components from BS21: (A) cholorogenic acid, (B) orientin, (C) isoorientin, (D) baicalin, (E) wogonoside, (F) baicalein, (G) tricin, (H) wogonin, and (I) chrysin. Identification was based on comparisons of retention times and UV spectra with those of commercial standards. The components were quantified based on the peak area at $270 \mathrm{~nm}$.

Table 1. BS21 extract constituents.

\begin{tabular}{ccccccccc}
\hline Chlorogenic Acid & Orientin & Isoorientin & Baicalin & Wogonoside & Baicalein & Tricin & Wogonin & Chrysin \\
\hline $2.9 \pm 0.10$ & $2.6 \pm 0.06$ & $28.1 \pm 0.35$ & $73.2 \pm 0.67$ & $8.9 \pm 0.27$ & $4.1 \pm 0.02$ & $2.9 \pm 0.50$ & $2.2 \pm 0.07$ & $0.2 \pm 0.04$ \\
\hline \multicolumn{7}{c}{ Data are expressed as mean \pm standard deviation (SD). }
\end{tabular}



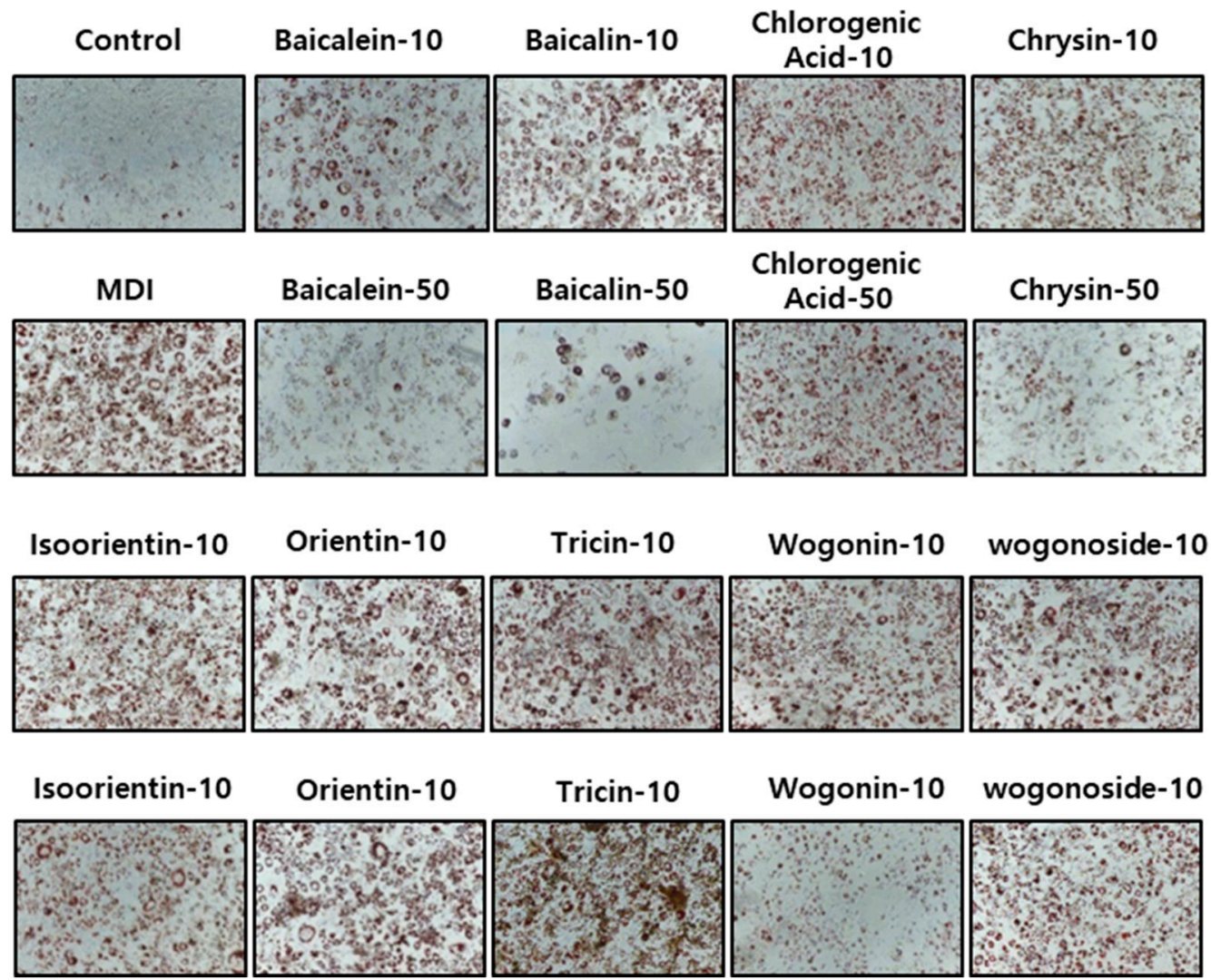

(A)

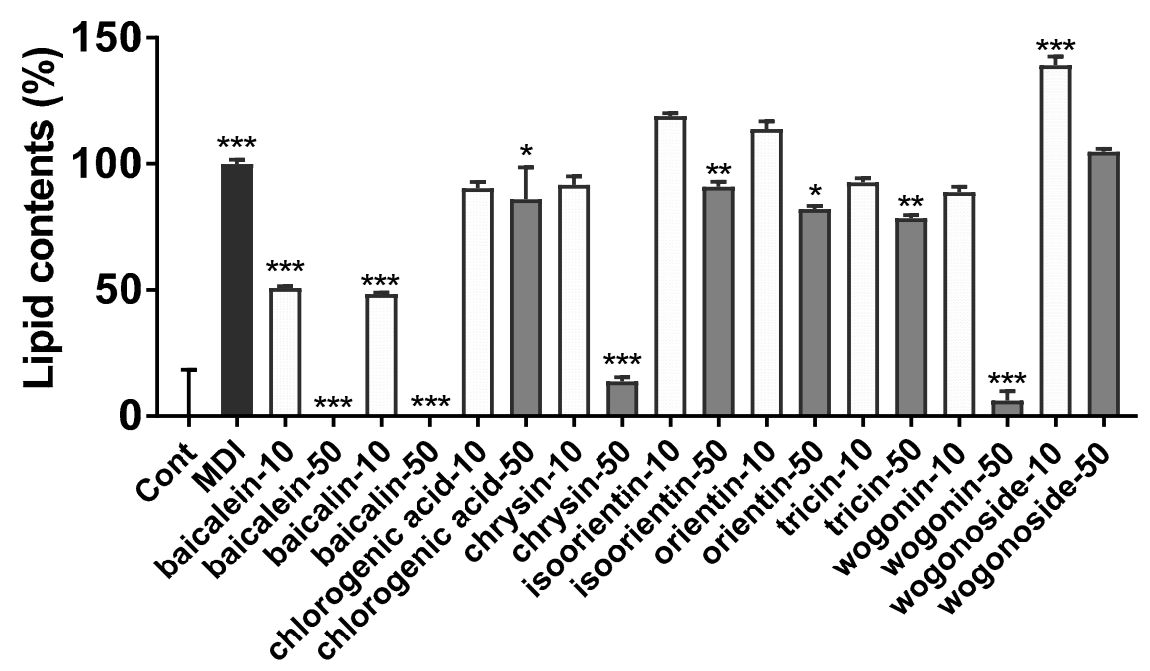

(B)

Figure 5. Cont. 


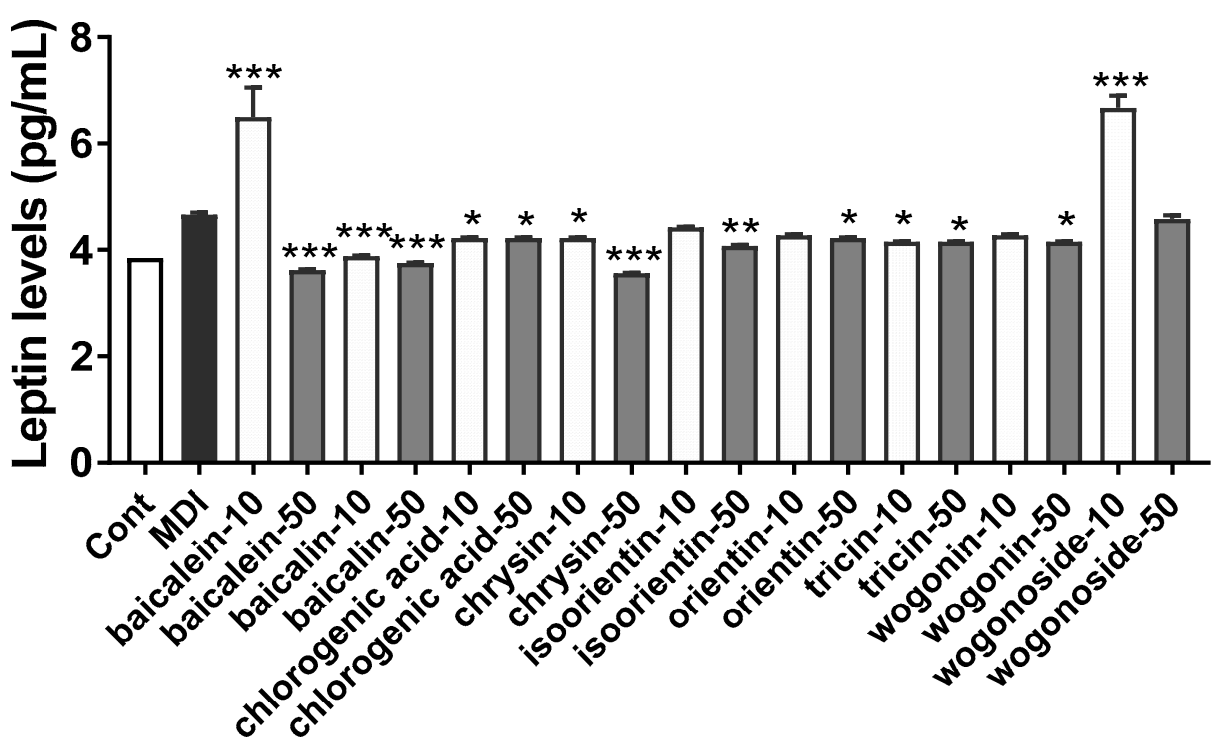

(C)

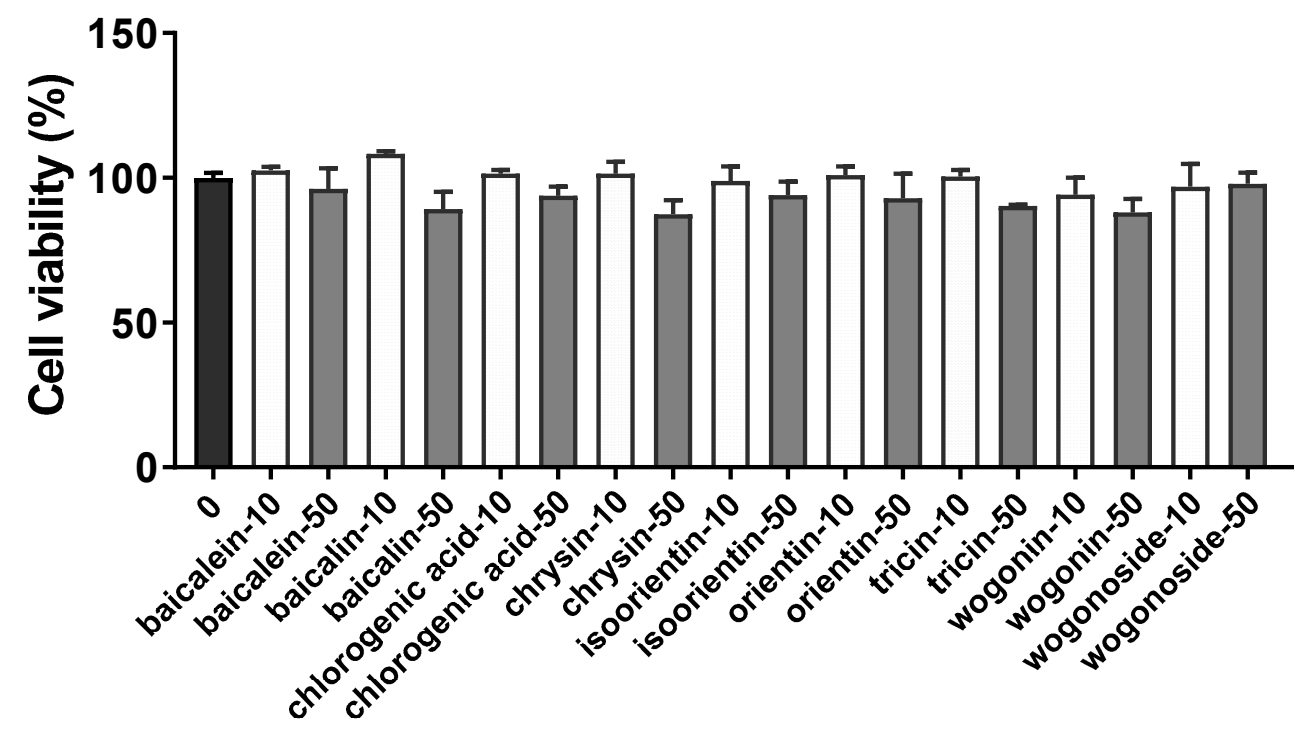

(D)

Figure 5. Effect of a 2:1 mixture of Phyllostachys pubescens and Scutellaria baicalensis (BS21) constituents on adipocyte differentiation in 3T3-L1 cells. (A) Oil Red O staining of intracellular triglycerides in 3T3-L1 cells. 3T3-L1 cells were treated with compounds (10 and $50 \mu \mathrm{g} / \mathrm{mL})$ during differentiation induction. (B) Relative densities of lipid contents. (C) Leptin levels. (D) Cell viability. Values are expressed as means $\pm \mathrm{SD}(n=3)$. Significant differences were observed between control (undifferentiated preadipocytes) and differentiated MDI cells: \# $p<0.05$, \#\# $p<0.01$, and \#\#\# $p<0.001$. Significant differences were observed between differentiated MDI (3-isobutyl-1-methylxanthine, dexamethasone, and insulin) cells and BS21-treated cells: ${ }^{*} p<0.05,{ }^{* *} p<0.01$, and ${ }^{* * *} p<0.001$.

\section{Discussion}

This study offers the first direct evidence on the anti-obesity effects of BS21 achieved through anti-adipogenesis and the promotion of browning. The results also provide insights into the regulatory mechanisms underlying those effects in 3T3-L1 adipocytes. 
PPAR $\gamma, C / E B P \alpha$, and SREBP-1c are major transcription factors involved in adipocyte differentiation, lipid accumulation, and glucose homeostasis $[19,20]$. These proteins regulate the expression of adipocyte-specific markers such as FAS, adiponectin, leptin, and aP2 [8,21]. In this study, we found that BS21 decreased the protein levels of transcription factors PPAR $\gamma$ (although it increased at $400 \mu \mathrm{g} / \mathrm{mL}$ concentration), $\mathrm{C} / \mathrm{EBP} \alpha$, and SREBP-1c as well as their downstream target proteins FAS, aP2, leptin, and adiponectin in 3T3-L1 adipocytes. BS21 did not enhance lipolysis and the protein levels of phospho-hormone-sensitive lipase (p-HSL), which is an important intracellular neutral lipase that degrades triglycerides by hydrolyzing the ester bond [22]. BS21 also increased protein levels of UCP1 and UCP2, which are mainly associated with thermogenesis and energy expenditure in brown and white adipocytes, respectively $[23,24]$. These results are supported by decreased fat accumulation in BS21-treated 3T3-L1 adipocytes. Collectively, our findings suggest that BS21 inhibited adipocyte differentiation by down-regulating lipogenesis and up-regulating thermogenesis during adipogenesis.

To further elucidate the mechanism underlying the anti-obesity effects of BS21, we measured marker proteins of BAT (PR domain containing 16 (PRDM16), peroxisome proliferator-activated receptor gamma co-activator 1-alpha (PGC1 $\alpha$ ), and $\mathrm{UCP} 1)$ involved in adaptive thermogenesis and the transition of WAT to brown-like adipose tissue [25]. In addition, the activated $\beta$-adrenergic signaling cascade (protein kinase A, AMPK, p38, and extracellular signal-regulated kinase) induces white fat browning and brown fat development by elevating PGC1 $\alpha$, PRDM16, PPAR $\gamma$, and UCP1 [26-29]. In this study, BS21 treatment induced AMPK activation and the expression of brown adipocyte marker proteins in 3T3-L1 adipocytes. In addition, BS21 treatment at $480 \mathrm{ug} / \mathrm{mL}$ increased protein levels of PPAR $\gamma$ despite the inhibition of adipogenesis. Previous studies reported that ginsenoside $\mathrm{Rb} 1$ and curcumin promote the browning of 3T3-L1 adipocytes through the induction of PPAR $\gamma[30,31]$. To identify its role in the BS21-induced browning pathway, we treated adipocytes with dorsomorphin, which is a selective inhibitor of AMPK. The arrest of brown fat expression marker protein UCP-1 upon AMPK inhibition reinforced our conclusion that the BS21 mixture induces browning via the AMPK-mediated pathway. Results from previous studies and the present work suggest that BS21 promotes the browning of white adipocytes through the up-regulation of AMPK $\alpha$-induced white browning proteins PGC1 $\alpha$, PRDM16, and UCP1.

Activated AMPK switches on mitochondrial fatty-acid oxidation and lipolysis [7] and turns off fatty-acid synthesis by inducing the phosphorylation and inactivation of acetyl-CoA carboxylase (ACC), which is an inhibitor of mitochondrial protein CPT1 activity [32]. BS21 treatment led to increased expressions of $\mathrm{p}-\mathrm{ACC}$ and CPT1. Therefore, the enhanced expression of these proteins is likely to reflect the stimulation of fat oxidation by BS21 treatment. However, even though AMPK activation was increased by BS21, lipolysis and HSL phosphorylation were decreased after BS21 treatment. These data indicate that the anti-obesity effects of BS21 are independent of the HSL enzyme. A recent study showed that AMPK activation inhibited lipolysis [33]. Berberine, a hypoglycemic agent with anti-dyslipidemia and anti-obesity activities, exerts anti-lipolytic effects mainly by reducing the inhibition of phosphodiesterase in 3T3-L1 cells, leading to a decrease in cAMP and HSL phosphorylation independent of the AMPK pathway [34]. These results suggest that the effect of BS21 on AMPK activation may be inhibited or independent of lipolysis.

These results suggest that BS21 may attenuate adipocyte differentiation by suppressing lipid synthesis and promoting fatty-acid oxidation by regulating AMPK activation. UPLC identified nine main compounds (chlorogenic acid, orientin, isoorientin, baicalin, wogonoside, baicalein, tricin, wogonin, and chrysin) in BS21. In our previous study, the two marker compounds isoorientin and baicalin were identified and quantified for the standardization of BS21 [18]. In this study, we identified seven compounds as well as isoorientin and baicalin. Eight constituents (except wogonoside) inhibited adipocyte differentiation and triglyceride accumulation and decreased leptin levels in 3T3-L1 cells. Consistent with our results, previous studies reported that baicalin, baicalein, wogonin, orientin, and isoorientin inhibited adipogenesis in 3T3-L1 adipocytes by decreasing expressions of C/EBP $\alpha$, SREBP-1c, and PPAR $\gamma[13,35-38]$. Chlorogenic acid was previously shown to inhibit adipocyte 
differentiation via AMPK activation [39,40]. Tricin suppressed the expression of transcription factors associated with adipocyte differentiation (PPAR $\gamma$ and $C / E B P \alpha)$ in obese mice fed a high-fat diet [41]. Collectively, the results suggest that these compounds are responsible for the anti-adipogenic activity of BS21. However, further investigation into the effects of these compounds on obesity is required.

The BS2 extract contains two plant extracts and a variety of compounds. A limitation of this study is that it is unclear if one or multiple components of BS21 are responsible for the observed effects on AMPK phosphorylation and thermogenesis. In addition, whether BS2 and its compounds decrease obesity in vivo using these energy expenditure mechanisms needs further investigation.

\section{Materials and Methods}

\subsection{Preparation of BS21}

P. pubescens leaves and S. baicalensis roots for the BS21 mixture were purchased from Zhenjiang KOC Biotech Co., Ltd. (Jiangsu, China). The dried P. pubescens leaves and S. baicalensis roots were extracted with $70 \%$ ethanol solution for $3 \mathrm{~h}$; then, the extract was prepared by mixing with a 2:1 ratio of P. pubescens (B) and S. baicalensis root (S) extracts. The lyophilized powder was dissolved in $10 \%$ dimethyl sulfoxide and filtered through a $0.22-\mu \mathrm{m}$ syringe filter to make the stock solution.

\subsection{Chemical Profiling of BS21}

A Waters ACQUITY UPLC system equipped with a quaternary pump, auto-sampler, and photodiode array detector with an ACQUITY UPLC BEH C18 column $(100 \times 2.1-\mathrm{mm}, 1.7-\mu \mathrm{m})$ was used for the chemical profiling of BS21 (Waters Corp., Milford, MA, USA). Elution was performed with $0.1 \%$ phosphoric acid solvent $\mathrm{A}$ and acetonitrile solvent $\mathrm{B}$. The elution conditions involved holding the starting mobile phase at $94 \% \mathrm{~A}$ and $6 \% \mathrm{~B}$ for $12 \mathrm{~min}$ and applying a gradient $(89 \% \mathrm{~A}: 11 \% \mathrm{~B}$ for $3 \mathrm{~min}, 80 \%$ A: 20\% B for $20 \mathrm{~min}, 40 \%$ A: 60\% B for $1 \mathrm{~min}$ ). A wash with 100\% B was applied for $2 \mathrm{~min}$, followed by equilibration at $94 \% \mathrm{~A}$ and $6 \% \mathrm{~B}$ for $2 \mathrm{~min}$. The separation temperature was maintained at $40{ }^{\circ} \mathrm{C}$ throughout the analysis, with a flow rate of $0.5 \mathrm{~mL} / \mathrm{min}$ and an injection volume of $3 \mu \mathrm{L}$. Each component was analyzed by Quadrupole Dalton (QDa) mass spectrometry, after which the reference standards were purchased from Sigma-Aldrich (St. Louis, MO, USA) and ChemFaces Inc. (Wuhan, Hubei, China), respectively. The retention time and UV spectra were compared and quantified. Components were quantified based on peak areas at $270 \mathrm{~nm}$.

\subsection{T3-L1 Cell Culture and Differentiation}

3T3-L1 cells (ATCC, Rockville, MD, USA) were incubated in Dulbecco's modified Eagle's medium (DMEM) supplemented with calf serum (10\%) and penicillin/streptomycin $(100 \mu \mathrm{g} / \mathrm{mL})$ in a humidified atmosphere of $5 \% \mathrm{CO}_{2}$ at $37{ }^{\circ} \mathrm{C}$. To induce the differentiation of 3T3-L1 preadipocytes, cells were incubated with DMEM containing 10\% fetal bovine serum (FBS), 3-isobutyl-1-methylxanthine (0.5 mM), dexamethasone $(1 \mu \mathrm{M})$, and insulin $(10 \mu \mathrm{g} / \mathrm{mL})$ (MDI differentiation media) after reaching confluence in 24-well plates. After 2 days of induction, cells were cultured in DMEM containing FBS (10\%) and insulin $(10 \mu \mathrm{g} / \mathrm{mL})$ for 2 days and subsequently maintained in DMEM containing FBS (10\%). Various concentrations $(60,120,240$, and $480 \mu \mathrm{g} / \mathrm{mL})$ of BS21 and its constituents $(10$ and $50 \mu \mathrm{g} / \mathrm{mL})$ were added along with the differentiation medium. To test the effects of p-AMPK inhibitor (dorsomorphin, Sigma, St. Louis, MO, USA), cells were supplemented with dorsomorphin ( $5 \mu \mathrm{M})$ in differentiation media until harvest. On day 7, differentiation was assessed based on Oil Red O staining and morphological changes. A cytotoxicity test of 3T3-L1 cells was performed to examine the effect of BS21 on 3T3-L1 cell viability using the 3-(4,5-dimethylthiazol-2-yl)-2,5-diphenyltetrazolium bromide (MTT) assay. The experiment was performed in triplicate, and cell viability was calculated relative to that of the BS21 no-treated control cells. 


\subsection{Oil Red O Staining}

For Oil Red O staining, the differentiated cells were washed gently with phosphate-buffered saline (PBS) and fixed with 10\% formalin for $15 \mathrm{~min}$. The fixed cells were stained with Oil Red O solution (in 60 isopropanol and $40 \%$ water) for $30 \mathrm{~min}$. After staining, the lipid droplets were visualized using an Olympus CKX41 microscope (Olympus, Tokyo, Japan) and photographed at $100 \times$ magnification using the Motic image Plus 2.0 program (Motic, Hong Kong, China).

\subsection{Measurement of Lipid Content}

To quantify intracellular lipids in Oil Red O-stained cells, the stained lipid droplets were dissolved in isopropanol (500 $\mu \mathrm{L} /$ well) for $30 \mathrm{~min}$, and the extracted dye $(100 \mu \mathrm{L})$ was transferred to a 96-well plate. Absorbance was measured at $520 \mathrm{~nm}$ using a spectrophotometer (BioRad, Hercules, CA, USA). The optical density of the fully differentiated adipocytes was set at $100 \%$ relative lipid content.

\subsection{Measurement of Adipokines}

After differentiation, leptin and adiponectin levels in the medium were measured using a leptin mouse enzyme-linked immunosorbent assay (ELISA) kit (Abcam, Cambridge, UK) and adiponectin mouse ELISA kit (R\&D systems, Minneapolis, MN, USA), respectively, following the manufacturer's manuals.

\subsection{Measurement of Glycerol Content}

Glycerol levels in the medium were measured using a glycerol assay kit (Sigma) with glycerol standards for calibration. Briefly, $100 \mu \mathrm{L}$ of free glycerol reagent reconstituted in distilled water was mixed with $10 \mu \mathrm{L}$ of the test sample. Thereafter, the mixtures were incubated at room temperature for $20 \mathrm{~min}$, and the solution absorbance was measured at $570 \mathrm{~nm}$ using a microplate reader.

\subsection{Western Blot Analysis}

Total protein from cells was extracted with PRO-PREP protein extraction solution (Intron, Seoul, Korea) according to the manufacturer's instructions. Total protein samples (15 $\mu \mathrm{g})$ were separated by sodium dodecyl sulfate polyacrylamide gel electrophoresis and transferred onto nitrocellulose membranes. The membranes were blocked with EzBlock Chemi (ATTO, Tokyo, Japan) and then incubated overnight with primary antibodies at $4{ }^{\circ} \mathrm{C}$. Primary antibodies to peroxisome proliferator-activated receptor (PPAR) $\gamma, \mathrm{CCAAT} /$ enhancer-binding protein $(\mathrm{C} / \mathrm{EBP}) \alpha$, sterol regulatory element-binding protein (SREBP)-1c, UCP2, and carnitine palmitoyltransferase (CPT) 1 were obtained from Santa Cruz Biotechnology (Dallas, TX, USA). Antibodies to adipocyte protein 2 (aP2), fatty-acid synthase (FAS), UCP1, AMPK $\alpha$, phospho-AMPK $\alpha$, and $\beta$-actin were purchased from Cell Signaling (Danvers, MA, USA). Antibodies to phospho-hormone-sensitive lipase (HSL), PR domain containing 16 (PRDM16), and PPAR $\gamma$ co-activator 1-alpha (PGC1 $\alpha$ ) were obtained from Abcam, and antibodies to phospho-Acetyl-CoA carboxylase (p-ACC) were purchased from Millipore (Billerica, MA, USA). After incubation with primary antibodies, the membranes were incubated with the corresponding horseradish peroxidase-conjugated secondary antibodies (Cell Signaling Technology) for $1 \mathrm{~h}$ at room temperature. Then, the membranes were treated with ECL chemiluminescent detection reagent (Amersham Bioscience, Little Chalfont, UK), and protein bands were visualized using LAS-1000 (Fujifilm, Tokyo, Japan). The relative band density was determined by densitometry with Image J software (National Institutes of Health, Bethesda, MD, USA).

\subsection{Statistical Analysis}

All experiments were repeated at least three times, and each experiment was performed in triplicate. Differences among experimental groups were evaluated using one-way analysis of variance 
followed by Dunnett's multiple-range tests. All data are presented as mean \pm standard deviation (SD). For all tests, $p<0.05$ was considered statistically significant.

\section{Conclusions}

The herbal mixture BS21 exerted anti-obesity effects in 3T3-L1 adipocytes by reducing adipogenesis and activating thermogenesis and browning via AMPK activation. Therefore, the data suggest that BS21 might be a potential therapeutic candidate for the prevention and treatment of obesity.

Author Contributions: Conceptualization, Y.-Y.S.; methodology, Y.-Y.S.; software, Y.-Y.S.; validation, Y.-Y.S., E.S. and G.I.; formal analysis, Y.-Y.S.; investigation, Y.-Y.S., E.S. and G.I.; resources, G.I.; data curation, Y.-Y.S.; writing-original draft preparation, Y.-Y.S.; writing-review and editing, Y.-Y.S.; visualization, Y.-Y.S. and E.S.; supervision, D.-S.K.; project administration, D.-S.K.; funding acquisition, D.-S.K. All authors have read and agreed to the published version of the manuscript."

Funding: This research was funded by the INNOPOLIS Foundation of Korea, grant numbers 2019-DD-RD-0039 and 2020-DD-RD-0420-01-201, and the KIOM of Korea, grant number KSN2012330.

Conflicts of Interest: The authors declare no conflict of interest.

\section{References}

1. Yumuk, V.; Tsigos, C.; Fried, M.; Schindler, K.; Busetto, L.; Micic, D.; Toplak, H. Obesity Management Task Force of the European Association for the Study of Obesity. Obes. Facts 2015, 8, 402-424. [CrossRef]

2. Bray, G.A. Drug Treatment of Obesity. Rev. Endocr. Metab. Disord. 2001, 2, 403-418. [CrossRef] [PubMed]

3. Spiegelman, B.M.; Flier, J.S. Obesity and the Regulation of Energy Balance. Cell 2001, 104, 531-543. [CrossRef]

4. Kim, G.W.; Lin, J.E.; Blomain, E.S.; Waldman, S.A. Anti-obesity pharmacotherapy: New drugs and emerging targets. Clin. Pharm. 2014, 95, 53-66.

5. Kajimura, S.; Saito, M. A New Era in Brown Adipose Tissue Biology: Molecular Control of Brown Fat Development and Energy Homeostasis. Annu. Rev. Physiol. 2014, 76, 225-249. [CrossRef] [PubMed]

6. Kim, K.; Nam, K.H.; Yi, S.A.; Park, J.W.; Han, J.-W.; Lee, J. Ginsenoside Rg3 Induces Browning of 3T3-L1 Adipocytes by Activating AMPK Signaling. Nutrients 2020, 12, 427. [CrossRef] [PubMed]

7. Hardie, D.G. AMPK: A key regulator of energy balance in the single cell and the whole organism. Int. J. Obes. 2008, 32, S7-S12. [CrossRef]

8. Son, Y.; Nam, J.-S.; Jang, M.-K.; Jung, I.-A.; Cho, S.-I.; Jung, M.-H. Antiobesity Activity of Vigna nakashimae Extract in High-Fat Diet-Induced Obesity. Biosci. Biotechnol. Biochem. 2013, 77, 332-338. [CrossRef]

9. Kahn, B.B.; Alquier, T.; Carling, D.; Hardie, D.G. AMP-activated protein kinase: Ancient energy gauge provides clues to modern understanding of metabolism. Cell Metab. 2005, 1, 15-25. [CrossRef]

10. Kwon, J.H.; Hwang, S.Y.; Han, J.-S. Bamboo (Phyllostachys bambusoides) leaf extracts inhibit adipogenesis by regulating adipogenic transcription factors and enzymes in 3T3-L1 adipocytes. Food Sci. Biotechnol. 2017, 26, 1037-1044. [CrossRef]

11. Cho, E.-A.; Kim, S.-Y.; Na, I.-H.; Kim, D.-C.; In, M.-J.; Chae, H.-J. Antioxidant and Anticoagulant Activities of Water and Ethanol Extracts of Phyllostachys pubescence Leaf Produced in Geoje. J. Appl. Biol. Chem. 2010, 53, 170-173. [CrossRef]

12. Yang, J.H.; Choi, M.-H.; Yang, S.H.; Cho, S.S.; Park, S.J.; Shin, H.-J.; Ki, S.H. Potent Anti-Inflammatory and Antiadipogenic Properties of Bamboo (Sasa coreana Nakai) Leaves Extract and Its Major Constituent Flavonoids. J. Agric. Food Chem. 2017, 65, 6665-6673. [CrossRef]

13. Poudel, B.; Nepali, S.; Xin, M.; Ki, H.-H.; Kim, Y.-H.; Kim, D.-K.; Lee, Y.-M. Flavonoids from Triticum aestivum inhibit adipogenesis in 3T3-L1 cells by upregulating the insig pathway. Mol. Med. Rep. 2015, 12, 3139-3145. [CrossRef] [PubMed]

14. Yoon, S.-B.; Lee, Y.-J.; Park, S.K.; Kim, H.-C.; Bae, H.; Kim, H.M.; Ko, S.-G.; Choi, H.Y.; Oh, M.S.; Park, W. Anti-inflammatory effects of Scutellaria baicalensis water extract on LPS-activated RAW 264.7 macrophages. J. Ethnopharmacol. 2009, 125, 286-290. [CrossRef]

15. Yoon, H.-J.; Park, Y.-S. Effects of Scutellaria baicalensis Water Extract on Lipid Metabolism and Antioxidant Defense System in Rats Fed High Fat Diet. J. Korean Soc. Food Sci. Nutr. 2010, 39, 219-226. [CrossRef] 
16. Song, K.H.; Lee, S.H.; Kim, B.-Y.; Park, A.Y.; Kim, J.Y. Extracts ofScutellaria baicalensisReduced Body Weight and Blood Triglyceride in db/db Mice. Phytother. Res. 2012, 27, 244-250. [CrossRef]

17. Hongxia, L.; Wu, M.; Li, H.; Dong, S.; Luo, E.; Gu, M.; Shen, X.; Jiang, Y.; Liu, Y.; Liu, H. Baicalin Attenuates High Fat Diet-Induced Obesity and Liver Dysfunction: Dose-Response and Potential Role of CaMKKß/AMPK/ACC Pathway. Cell Physiol. Biochem. 2015, 35, 2349-2359. [CrossRef]

18. Kim, D.-S.; Kim, S.-H.; Cha, J. Antiobesity Effects of the Combined Plant Extracts Varying the Combination Ratio of Phyllostachys pubescens Leaf Extract and Scutellaria baicalensis Root Extract. Evid.-Based Complement. Altern. Med. 2016, 2016, 1-11. [CrossRef]

19. Schoonjans, K.; Staels, B.; Auwerx, J. The peroxisome proliferator activated receptors (PPARs) and their effects on lipid metabolism and adipocyte differentiation. Biochim. Biophys. Acta (BBA) Lipids Lipid Metab. 1996, 1302, 93-109. [CrossRef]

20. Rosen, E.D.; Walkey, C.J.; Puigserver, P.; Spiegelman, B.M. Transcriptional regulation of adipogenesis. Genes Dev. 2000, 14, 1293-1307.

21. Kliewer, S.A.; Willson, T.M. The nuclear receptor PPARgamma - bigger than fat. Curr. Opin. Genet. Dev. 1998, 8, 576-581. [CrossRef]

22. Bezaire, V.; Mairal, A.; Ribet, C.; Lefort, C.; Girousse, A.; Jocken, J.; Laurencikiene, J.; Anesia, R.; Rodriguez, A.-M.; Ryden, M.; et al. Contribution of Adipose Triglyceride Lipase and Hormone-sensitive Lipase to Lipolysis in hMADS Adipocytes. J. Biol. Chem. 2009, 284, 18282-18291. [CrossRef] [PubMed]

23. Dulloo, A.G.; Seydoux, J.; Jacquet, J. Adaptive thermogenesis and uncoupling proteins: A reappraisal of their roles in fat metabolism and energy balance. Physiol. Behav. 2004, 83, 587-602. [CrossRef] [PubMed]

24. Sung, Y.-Y.; Kim, D.-S.; Kim, H.K. Viola mandshurica ethanolic extract prevents high-fat-diet-induced obesity in mice by activating AMP-activated protein kinase. Environ. Toxicol. Pharmacol. 2014, 38, 41-50. [CrossRef] [PubMed]

25. Park, S.J.; Park, M.; Sharma, A.; Kim, K.; Lee, H.J. Black ginseng and ginsenosde Rb1 promote browning by inducing UCP1 expression in 3T3-L1 and primary white adipocytes. Nutrients 2019, 11, 2747. [CrossRef]

26. Yan, M.; Audet-Walsh, É; Manteghi, S.; Dufour, C.R.; Walker, B.; Baba, M.; St-Pierre, J.; Giguère, V.; Pause, A. Chronic AMPK activation via loss of FLCN induces functional beige adipose tissue through PGC-1 $\alpha / E R R \alpha$. Genes Dev. 2016, 30, 1034-1046. [CrossRef] [PubMed]

27. Yang, Q.; Liang, X.; Sun, X.; Zhang, L.; Fu, X.; Rogers, C.J.; Berim, A.; Zhang, S.; Wang, S.; Wang, B.; et al. AMPK $/ \alpha$-Ketoglutarate Axis Dynamically Mediates DNA Demethylation in the Prdm16 Promoter and Brown Adipogenesis. Cell Metab. 2016, 24, 542-554. [CrossRef]

28. Lanzi, C.R.; Perdicaro, D.J.; Landa, M.S.; Fontana, A.; Antoniolli, A.; Miatello, R.M.; Oteiza, P.I.; Prieto, M.A.V. Grape pomace extract induced beige cells in white adipose tissue from rats and in 3T3-L1 adipocytes. J. Nutr. Biochem. 2018, 56, 224-233. [CrossRef]

29. Seo, Y.-J.; Kim, K.-J.; Choi, J.; Koh, E.-J.; Lee, B.-Y. Spirulina maxima Extract Reduces Obesity through Suppression of Adipogenesis and Activation of Browning in 3T3-L1 Cells and High-Fat Diet-Induced Obese Mice. Nutrients 2018, 10, 712. [CrossRef]

30. Mu, Q.; Fang, X.; Li, X.; Zhao, D.; Mo, F.; Jiang, G.; Yu, N.; Zhang, Y.; Guo, Y.; Fu, M.; et al. Ginsenoside Rb1 promotes browning through regulation of PPAR $\gamma$ in 3T3-L1 adipocytes. Biochem. Biophys. Res. Commun. 2015, 466, 530-535. [CrossRef]

31. Lone, J.; Choi, J.H.; Kim, S.W.; Yun, J.W. Curcumin induces brown fat-like phenotype in 3T3-L1 and primary white adipocytes. J. Nutr. Biochem. 2016, 27, 193-202. [CrossRef] [PubMed]

32. Kim, S.-J.; Jung, J.Y.; Kim, H.W.; Park, T. Anti-obesity effects of Juniperus chinensis extract are associated with increased AMP-activated protein kinase expression and phosphorylation in the visceral adipose tissue of rats. Biol. Pharm. Bull. 2008, 31, 1415-1421. [CrossRef]

33. Daval, M.; Diot-Dupuy, F.; Bazin, R.; Hainault, I.; Viollet, B.; Vaulont, S.; Hajduch, E.; Ferré, P.; Foufelle, F. Anti-lipolytic Action of AMP-activated Protein Kinase in Rodent Adipocytes. J. Biol. Chem. 2005, 280, 25250-25257. [CrossRef] [PubMed]

34. Zhou, L.; Wang, X.; Yang, Y.; Wu, L.; Li, F.; Zhang, R.; Yuan, G.; Wang, N.; Chen, M.; Ning, G. Berberine attenuates cAMP-induced lipolysis via reducing the inhibition of phosphodiesterase in 3T3-L1 adipocytes. Biochim. Biophys. Acta (BBA) Mol. Basis Dis. 2011, 1812, 527-535. [CrossRef] [PubMed]

35. Kim, J.; Lee, I.; Seo, J.; Jung, M.; Kim, Y.; Yim, N.; Bae, K. Vitexin, orientin and other flavonoids from Spirodela polyrhiza inhibit adipogenesis in 3T3-L1 cells. Phytother. Res. 2010, 24, 1543-1548. [CrossRef] 
36. Kwak, D.H.; Lee, J.H.; Kim, D.G.; Kim, T.; Lee, K.J.; Ma, J.Y. Inhibitory effects of Hwangryunhaedok-Tang in 3T3-L1 adipogenesis by regulation of Raf/MEK1/ERK1/2 pathway and PDK1/Akt phosphorylation. Evid.-Based Complement. Alternat. Med. 2013, 2013, 413906. [CrossRef]

37. Kwak, D.H.; Lee, J.H.; Song, K.H.; Ma, J.Y. Inhibitory effects of baicalin in the early stage of 3T3-L1 preadipocytes differentiation by down-regulation of PDK1/Akt phosphorylation. Mol. Cell Biochem. 2014, 385, 257-264. [CrossRef]

38. Nakao, Y.; Yoshihara, H.; Fujimori, K. Suppression of Very Early Stage of Adipogenesis by Baicalein, a Plant-Derived Flavonoid through Reduced Akt-C/EBP $\alpha$-GLUT4 Signaling-Mediated Glucose Uptake in 3T3-L1 Adipocytes. PLoS ONE 2016, 11, e0163640. [CrossRef]

39. Sung, Y.Y.; Kim, D.S.; Kim, H.K. Akebia quinata extract exerts anti-obesity and hypolipidemic effects in high-fat diet-fed mice and 3T3-L1 adipocytes. J. Ethnopharmacol. 2015, 168, 17-24. [CrossRef]

40. Xu, M.; Yang, L.; Zhu, Y.; Liao, M.; Chu, L.; Li, X.; Lin, L.; Zheng, G. Collaborative effects of chlorogenic acid and caffeine on lipid metabolism via the AMPK $\alpha$-LXR $\alpha / S R E B P-1 c$ pathway in high-fat diet-induced obese mice. Food Funct. 2019, 10, 7489-7497. [CrossRef]

41. Lee, D.; Imm, J.-Y. Antiobesity Effect of Tricin, a Methylated Cereal Flavone, in High-Fat-Diet-Induced Obese Mice. J. Agric. Food Chem. 2018, 66, 9989-9994. [CrossRef] [PubMed]

Publisher's Note: MDPI stays neutral with regard to jurisdictional claims in published maps and institutional affiliations.

(C) 2020 by the authors. Licensee MDPI, Basel, Switzerland. This article is an open access article distributed under the terms and conditions of the Creative Commons Attribution (CC BY) license (http://creativecommons.org/licenses/by/4.0/). 